\title{
KEMAMPUAN MENULIS PUISI \\ MENGGUNAKAN GAMBAR TOKOH IDOLA SISWA KELAS VII A SMP NEGERI SATU ATAP PETALING TAHUN PELAJARAN 2016/2017
}

\author{
Rudi Hariyanto ${ }^{1}$, Abdoel Gafar ${ }^{2}$, Firman Tara ${ }^{3}$ \\ Program Studi Pendidikan Bahasa dan Sastra Indonesia, \\ Fakultas Keguruan dan Ilmu Pendidikan, Universitas Batanghari, \\ Jambi \\ Gafar35@yahoo.co.id \\ Firmantara14@gamil.com
}

\begin{abstract}
This research is intended to describe students ability in wiring poetry by using a picture of their idols in class VII A SMP Negeri Satu Atap Petaling Academic Year 2016/2017. This research uses quantitative descriptive method. The data is taken from students poetry in decribing their idols. This researh uses quantitative analysis. The data analysis is counted by using the percentage of students assessment in writing poetry. The data of the research is 25 students. Based on students result in writing poetry by describing their idols at class VII A SMPN Satu Atap Petaling Academic Year 2016/2017, it can be seen that there are 3 students who got 87,5 who fall into good category; there is 1 student who got 81,25 tat falls into very good category; there are 9 students who got 75 that fall into good category; there are 6 students who got 68,75 hat fall into good categroy; and there are 6 students who got 62,5 that fall into fair category. From those 25 students, the total score is 289 with the total score is 1806,5 , and the mean is 72,25 that falls into good category. Hus, students ability in writing poetry in decribing their idols at class students of VII A SMP Negeri Satu Atap Petaling Academic Year 2016/2017 fall into good category.
\end{abstract}

Key Words : ability, writing poetry, picturing idols.

\footnotetext{
${ }^{1}$ Mahasiswa Program Studi Pendidikan Bahasa dan Sastra Indonesia, Fakultas Keguruan dan Ilmu Pendidikan, Universitas Batanghari, Jambi

${ }^{2}$ Dosen Program Studi Pendidikan Bahasa dan Sastra Indonesia ,Fakultas Keguruan dan Ilmu Pendidikan, Universitas Batanghari, Jambi

${ }^{3}$ Dosen Program Studi Pendidikan Bahasa dan Sastra Indonesia, Fakultas Keguruan dan Ilmu Pendidikan, Universitas Batanghari, Jambi
} 


\section{PENDAHULUAN}

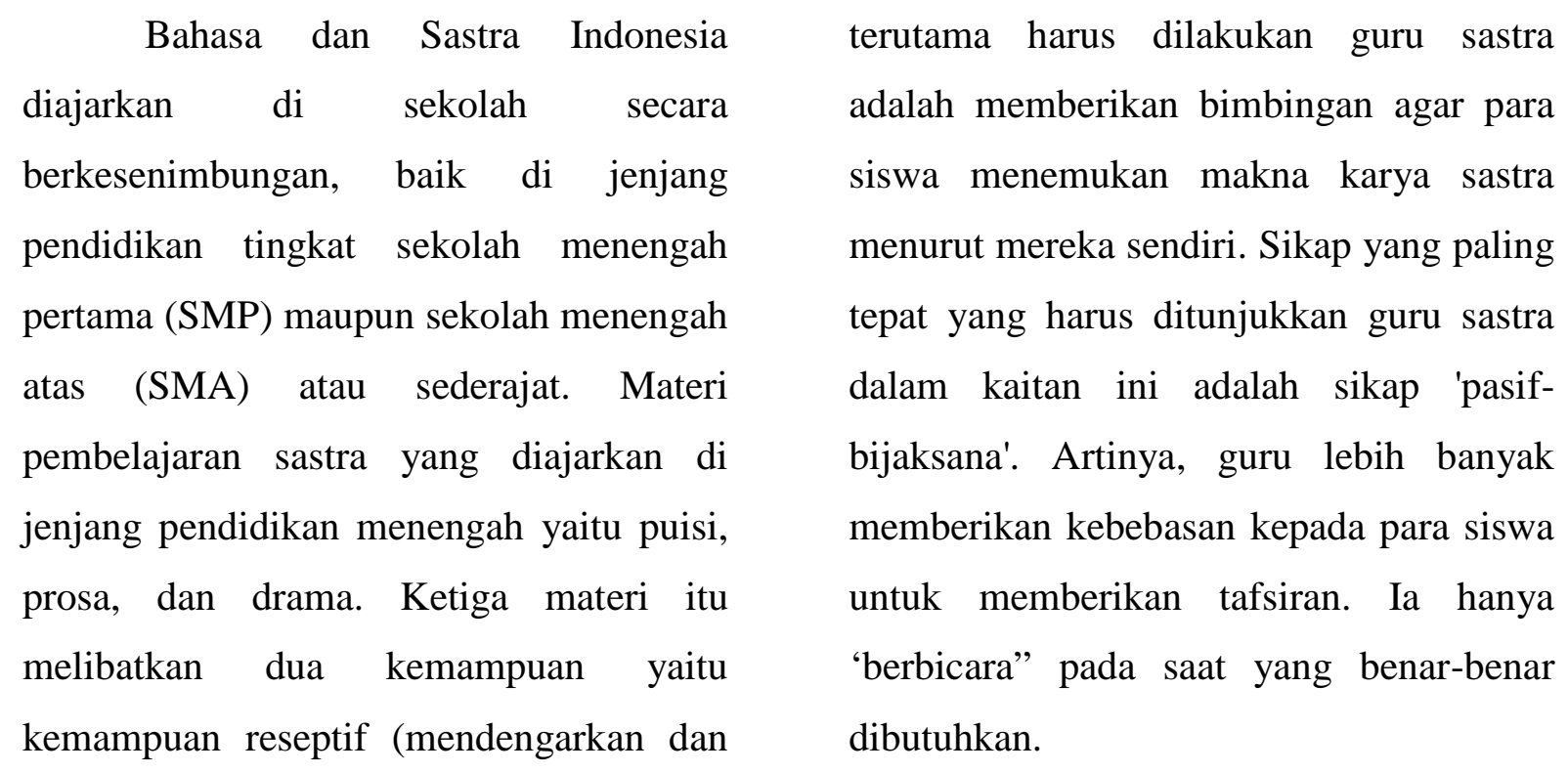
membaca) dan kemampuan produktif (berbicara dan menulis). Sebelum sampai pada pembicaraan mengenai teori pembelajaran apresiasi sastra, ada baiknya terlebih dahulu mengetahui prinsip ganda karya sastra. Karya sastra memiliki prinsip ganda sebagai berikut: pertama, sastra sebagai pengalaman dan kedua, sastra sebagai bahasa (Suyitno, 2009:56).

Sastra sebagai pengalaman artinya sesuatu yang harus dihayati, dinikmati, dirasakan dan dipikirkan. Dengan demikian, berdasarkan prinsip ini karya sastra yang kita sajikan dalam pengajaran apresiasi sastra hendaknya menyajikan pengalaman baru yang kaya bagi para siswa. Oleh karena itu, karya sastra tersebut harus memberikan pengaruh kepada kehidupan para siswa. Hal yang
Prinsip ganda berikutnya adalah sastra sebagai bahasa. Sebagai sebuah komunikasi yang menggunakan bahasa, karya sastra menggunakan teknik-teknik pemakaian unsur kebahasaan, misalnya pernyataan, keterangan, pembandingan, ungkapan, nada, dan tekanan kalimat. Dengan demikian, karya sastra harus dipelajari melalui analisis verbal. Guru sastra hendaknya memahami seluk-beluk kebahasaan yang dipakai dalam karya sastra yang disajikan kepada para siswa.

Jenis pembelajaran menulis yang diajarkan di sekolah khususnya pada siswa SMP, salah satunya adalah pembelajaran menulis puisi. Puisi merupakan salah satu contoh hasil menulis. Pengungkapan gagasan dalam menulis puisi harus dilakukan secara tepat agar gagasan, 
pendapat, dan perasaan penulis puisi dapat terasa atau dirasakan oleh pembaca. Untuk mendapatkan tujuan tersebut, menulis puisi harus didukung dengan penggunaan bahasa sastra dan majas yang tepat. Sasaran utama keterampilan menulis adalah tindak tanduk yang dijalin dan dirangkaikan menjadi sebuah peristiwa yang terjadi dalam suatu kesatuan waktu.

Kegiatan ini diharapkan mampu memberikan jawaban untuk mengetahui tingkat kemampuan siswa dalam menulis puisi. Berdasarkan permasalahan di atas, penulis tertarik mengadakan penelitian tentang kemampuan menulis puisi menggunakan gambar tokoh idola pada pembelajaran bahasa Indonesia. Peneliti menganggap perlu diadakan penelitian dengan judul Kemampuan Menulis Puisi dengan Menggunakan Gambar Tokoh Idola pada Siswa kelas VII A SMP Negeri Satu Atap Petaling Tahun Pelajaran 2016/2017.

Berdasarkan pada latar belakang masalah di atas, maka dapat rumusan masalah pada penelitian ini adalah Bagaimana kemampuan menulis puisi dengan menggunakan gambar tokoh idola pada siswa kelas VII A SMP Negeri Satu Atap Petaling Tahun Pelajaran 2016/2017?

Tujuan merupakan arah dari suatu penelitian. Berdasarkan rumusan masalah di atas, maka tujuan yang ingin dicapai dalam penelitian ini ialah untuk mendeskripsikan kemampuan menulis puisi dengan menggunakan gambar tokoh idola pada siswa kelas VII A SMP Negeri Satu Atap Petaling Tahun Pelajaran 2016/2017.

Manfaat penelitian merupakan dampak dari tercapainya tujuan dan terjawabnya rumusan masalah secara akurat. Manfaat yang diharapkan dari penelitian ini adalah:

Secara teoretis, hasil penelitian ini diharapkan dapat dipergunakan untuk memberikan masukan teoretis tentang menulis puisi dalam pembelajaran bahasa Indonesia di SMP. Hasil penelitian ini dapat dijadikan acuan dalam upaya meningkatkan keterampilan menulis puisi juga dapat menambah ilmu pengetahuan terutama dalam menulis puisi.

Adapun manfaat secara praktis yang dapat diharapkan dari penelitian ini adalah sebagai berikut:

1. Hasil penelitian ini bermanfaat bagi guru dalam memperoleh masukan tentang gambaran yang nyata atas kemampuan siswa menulis puisi sehingga dapat ditindaklanjuti.

2. Hasil penelitian ini akan bermanfaat bagi siswa sebagai gambaran nyata atas kemampuan menulis yang dimilikinya 
sehingga dapat dikembangkan dengan lebih baik.

3. Hasil penelitian ini akan memberikan sumbangan dalam menentukan kebijaksanaan sekolah khususnya dalam pembelajaran menulis.

4. Bagi peneliti berikutnya agar hasil penelitian ini dapat dijadikan referensi untuk melakukan penelitian yang sama dengan kajian yang berbeda dengan penulis lakukan.

\section{METODE PENELITIAN}

"Metode penelitian merupakan sesuatu yang sangat penting karena berhasil tidaknya, demikian rendahnya kualitas hasil penelitian sangat ditentukan oleh ketepatan peneliti dalam memilih metode peneliti" (Arikunto, 2010:22). Penelitian ini menggunakan metode penelitian kuantitatif. "Penelitian deskriptif yaitu penelitian yang berusaha untuk menuturkan pemecahan masalah yang ada sekarang berdasarkan data-data jadi ia juga menyajikan data, menganalisis dan menginterprestasi” (Ahmadi, 2001:65).

Penelitian deskriptif digunakan untuk memecahkan permasalahan yang sedang dihadapi pada situasi sekarang. Dilakukan dengan menempuh langkahlangkah pengumpulan data, klasifikasi dan analisis pengolahan data, membuat penggambaran tentang suatu keadaan objek dan deskripsi situasi. "Kualitatif adalah kata yang berupa informasi berbentuk kalimat yang memberi gambaran tentang ekspresi siswa berkaitan dengan tingkat pemahaman terhadap suatu mata pelajaran (kognitif), pandangan atau sikap siswa terhadap metode belajar yang baru (afektif) aktivitas siswa mengikuti pelajaran perhatian dan antusias dalam belajar" (Kunandar, 2008:128).

Dengan demikian, dapat disimpulkan metode deskriptif kuantitatif ini bermaksud mendeskripsikan kemampuan menulis puisi dengan menggunakan gambar tokoh idola di kelas VII A SMP Negeri Satu Atap Petaling.

Populasi dan sampel adalah alat yang dapat digunakan dalam memperoleh data. Dalam penelitian kualitatif, populasi diartikan sebagai wilayah generalisasi yang terdiri atas: objek/subjek yang mempunyai kualitas dan karakteristik tertentu yang ditetapkan oleh peneliti untuk dipelajari dan kemudian ditarik kesimpulannya. "Populasi adalah keseluruhan subjek penelitian yang akan diteliti” (Setriyadi, 2007:174). Dalam penelitian ini, yang menjadi populasi penelitian adalah siswa kelas kelas VII A SMP Negeri Satu Atap Petaling, yang berjumlah 25 orang siswa. 
"Sampel adalah sebagian atau wakil dari populasi yang diteliti" (Arikunto, 2010:117). Pengambilan sampel harus dilakukan sedemikian rupa sehingga diperoleh sampel yang benarbenar dapat berfungsi sebagai populasi yang sebenarnya. Adapun yang menjadi sampel dalam penelitian ini adalah siswa kelas VII A SMP Negeri Satu Atap Petaling yang berjumlah satu kelas dengan jumlah siswa sebanyak 25 , terdiri atas lakilaki 11 orang dan perempuan 14 orang. Penentuan sampel dilakukan dengan menggunakan teknik total sampling yaitu jumlah sampel sama dengan jumlah populasi.

Terdapat dua jenis data dalam penelitian ini, yaitu data primer dan data sekunder. "Data primer adalah data yang di peroleh secara langsung oleh peneliti” (Subagyo, 2006:87). Data primer di dalam penelitian ini adalah tugas menulis puisi dengan menggunakan gambar tokoh idola yang peneliti berikan kepada siswa. "Data sekunder adalah data yang di peroleh dengan menggunakan studi literatur yang di lakukan terhadap banyak buku yang berkaitan dengan penelitian" (Sugiyono, 2005: 62). Data sekunder di dalam penelitian ini adalah teori yang diambil dari buku-buku atau literartur seperti buku keterampilan menulis puisi, buku penelitian pendidikan, buku tentang media, dan buku tentang ejaan.

Teknik pengumpulan data merupakan langkah yang paling utama di dalam penelitian, karena tujuan utama dari penelitian adalah mendapatkan data. Adapun tehnik pengumpulan data dalam penelitian adalah sebagai berikut:

1. Observasi dilakukan untuk mengamati pembelajaran, guru, siswa, dan kurikulum di sekolah tersebut.

2. Studi pustaka adalah teknik pengumpulan data dengan penelaahan terhadap buku-buku, literartur, catatancatatan, dan laporan yang berkaitan dengan permasalahan yang sedang diteliti.

3. Penugasan dilakukan untuk mendapatkan data primer. Siswa diberikan tugas menulis puisi dengan menggunakan gambar tokoh idola. Kemudian tugas siswa tersebut dianalisis.

Teknik analisis data adalah suatu kegiatan untuk mengatur, mengurutkan, dan mengelompokkan, serta memberi kode/tanda, sehingga diperoleh suatu temuan berdasarkan fokus atau masalah yang akan dipecahkan.

1. Setelah mengumpulkan data dengan teknik-teknik pengumpulan data yang telah di lakukan. Selanjutnya peneliti 
memberikan skor untuk masing-masing kriteria yang akan di nilai. dengan menggunakan rumus sebagai berikut:

$$
\text { Skor }=\frac{\text { Skor Mentah }}{\text { Skor Maksimum }} \times \mathbf{1 0 0}
$$

(Sudijono, $2011: 318$ )

2. Setelah memberikan skor dengan menggunakan rumus di atas, selanjutnya peneliti mencari rata-rata masing-masing siswa dengan rumus sebagai berikut:

$$
\begin{aligned}
& \mathrm{M}_{\mathrm{x}}=\frac{\sum \mathrm{X}}{N} \\
& \text { Keterangan : } \\
& \mathrm{Mx} \quad \text { : Nilai rata-rata } \\
& \sum \mathrm{X} \quad \text { : Jumlah skor nilai siswa } \\
& \mathrm{N} \quad \text { : Jumlah siswa } \\
& \text { (Sudijono, } 2011: 327 \text { ) }
\end{aligned}
$$

3. Menganalisis nilai atau data-data yang telah di peroleh menjadi predikat dengan kriteria penskoran sebagai berikut:

4. Mendeskripsikan skor yang telah diperoleh siswa, dengan tujuan untuk memperjelas keberhasilan menulis puisi dengan menggunakan gambar tokoh idola.

5. Setelah selesai mendeskripsikan hasil dari penilaan maka dilakukan tahap akhir dengan membuat kesimpulan.

\section{HASIL DAN PEMBAHASAN}

Hasil penelitian digunakan untuk mengetahui kemampuan siswa pada pembelajaran menulis puisi. Berdasarkan hasil penelitian tentang kemampuan menulis puisi dengan menggunakan gambar tokoh idola pada siswa kelas VII A SMP Negeri Satu Atap Petaling Tahun Pelajaran 2016/2017 dapat dijelaskan seperti di bawah ini.

Sebelum kegiatan penelitian dilaksanakan penulis menyiapkan perangkat pembelajaran yang digunakan di antaranya: RPP, media gambar tokoh idola, lembar kerja siswa dan instrumen penelitian. Sebelum materi disampaikan ada tahapan yang dilakukan peneliti dalam membuka pelajaran, memberikan materi pembelajaran dengan menjelaskan pengertian puisi, unsur-unsur puisi dan langkah-langkah menulis puisi, memberikan tugas.

Berdasarkan hasil analisis data, diperoleh skor sebagai berikut. Pada aspek diksi 5 siswa mendapat skor 4; 15 siswa mendapat skor 3; dan 5 siswa mendapat skor 2 dengan jumlah 75. Pada aspek gaya bahasa, siswa yang mendapat skor 4 sebanyak 3 siswa; yang mendapat skor 3 sebanyak 14 siswa; dan yang mendapat skor 2 sebanyak 7 siswa dengan jumlah 71. Pada aspek imajinasi, siswa yang mendapat skor 4 sebanyak 4 siswa; yang 
mendapat skor 3 sebanyak 14 siswa; dan yang mendapat skor 2 sebanyak 7 siswa dengan jumlah 72. Dan berdasarkan aspek tema, siswa mendapat skor 4 sebanyak 3 siswa; yang mendapat skor 3 sebanyak 15 siswa; dan 7 siswa mendapat skor 2, dengan jumlah skor 47. Berdasarkan jumlah skor pada setiap aspek penelitian, maka didapatkan jumlah skor keseluruhannya adalah 289.

Berdasarkan data di atas, maka diperoleh nilai kemampuan menulis puisi dengan menggunakan gambar tokoh idola sebagai berikut: jumlah siswa yang mendapatkan nilai 87,5 ada 3 orang; siswa yang mendapatkan nilai 81,25 ada 1 orang; siswa yang mendapatkan nilai 75 ada 9 orang; siswa yang mendapatkan nilai 68,25 ada 6 orang; dan nilai 62,5 ada 6 orang.

Secara rinci dapat dilihat pada diagram lingkaran berikut ini

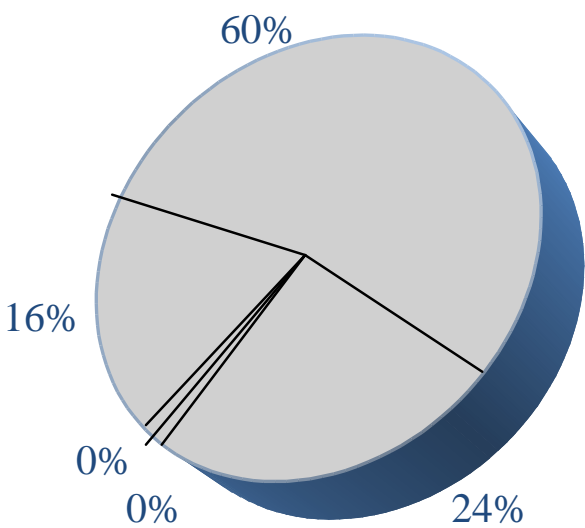

\section{Grafik 1. Persentase Hasil Menulis Puisi Siswa Menggunakan Gambar Tokoh Idola di Kelas VII A SMP Negeri Satu Atap Petaling Tahun Pelajaran 2016/2017}

Berdasarkan tabel di atas maka diperoleh data persentase siswa sebagai berikut : (1) siswa yang mendapat predikat yang sangat baik $16 \%$ (4), siswa yang mendapatkan nilai baik 60\% (15), dan siswa yang mendapatkan nilai cukup ada $24 \%$ (6). Tabel skala penilaian digunakan untuk melihat berapa frekuensi, predikat, dan persentase yang diperoleh siswa.
Frekuensi jumlah siswa yang mendapatkan predikat sangat baik ada 4 orang, frekuensi jumlah siswa yang mendapatkan predikat baik ada 15 orang, dan frekuensi jumlah siswa yang mendapatkan cukup ada 6 orang. 
Tabel 1. Skala Penilaian Keberhasilan Menulis Puisi dengan Menggunakan Gambar Tokoh Idola di Kelas VII A SMP Negeri Satu Atap Petaling Tahun Pelajaran 2016/2017

\begin{tabular}{cccccc}
\hline No & Nilai & Predikat & Frekuensi & Nilai Huruf & Persentase (\%) \\
\hline 1 & 80 ke atas & Sangat Baik & 4 & A & $16 \%$ \\
\hline 2 & $66-79$ & Baik & 15 & B & $60 \%$ \\
\hline 3 & $56-65$ & Cukup & 6 & C & $24 \%$ \\
\hline 4 & $45-55$ & Kurang & - & D & - \\
\hline 5 & 45 ke bawah & Gagal & - & E & - \\
\hline Jumlah & & & 25 & & $100 \%$ \\
\hline
\end{tabular}

\section{SIMPULAN}

Berdasarkan hasil penelitian, dapat disimpulkan bahwa dalam pelaksanaan pembelajaran menulis puisi dengan menggunakan gambar tokoh idola siswa di kelas VII A SMP Negeri Satu Atap Petaling Tahun Pelajaran 2016/2017 dapat dikategorikan baik. Kegiatan pembelajaran berjalan dengan baik, dikarenakan media dapat membantu dan membina kerja sama antar siswa dengan baik dan membuat siswa menjadi lebih aktif dalam pembelajaran. Setiap siswa dapat memberikan nilai hasil menulis puisi dengan baik dan efektif. Hasil pemerolehan nilai secara keseluruhan berjumlah 1806,25 dengan rata-rata 72,25, sedangkan berdasarkan skala penilaian, terdapat 4 orang siswa yang mendapatkan nilai sangat baik, 15 orang siswa mendapatkan nilai yang baik, dan 6 orang siswa mendapatkan nilai yang cukup.

\section{DAFTAR PUSTAKA}

Setriyadi. 2007. Metode Penelitian. Yogyakarta: Pustaka Pelajar. Subagyo, Joko. P. (2006). Metode Penelitian dalam Teori dan Praktek. Jakarta: Rineka Cipta.

Sugiyono. (2011). Metode Penelitian

Kuantitatif dan Kualitatif $R \& D$.

Bandung: Alfabeta.

Suyitno. (2009). Apresiasi Puisi dan

Prosa. Surakarta: Lembaga

Pengembangan Pendidikan (LLP)

UNS. 